\title{
The Utilization of Modified Chitosan from Shrimp Shell As Photodegradation of Pesticides Paraquat Dichloride
}

\author{
Risfidian Mohadi ${ }^{1 *}$, Neza Rahayu Palapa ${ }^{2}$, Rudi Hartono ${ }^{1}$, Nurlisa Hidayati ${ }^{1}$, Rozirwan ${ }^{3}$ \\ ${ }^{1}$ Department of Chemistry, Faculty of Mathematics and Natural Sciences, Sriwijaya University, South Sumatra, Indonesia \\ ${ }^{2}$ Graduate School of Faculty of Mathematics and Natural Sciences, Sriwijaya University, Palembang, South Sumatra, Indonesia \\ ${ }^{3}$ Department of Marine Science, Faculty of Mathematics and Natural Sciences, University of Sriwijaya, South Sumatra Indonesia \\ *Corresponding author: risfidian.mohadi@unsri.ac.id
}

\begin{abstract}
In this study, the chitosan modification of shrimp shell has been made by impregnated the chitosan from shrimp shell with $\mathrm{Ti} / \mathrm{ZrO}_{2}$ and $\mathrm{ZrO}_{2}$ to formed composite of chitosan- $\mathrm{Ti} / \mathrm{ZrO}_{2}$ and chitosan- $\mathrm{ZrO}_{2}$. These composites were made by immobilization technique and characterized by FTIR and SEM-EDX. The chitosan- $\mathrm{Ti} / \mathrm{ZrO}_{2}$ and chitosan- $\mathrm{ZrO}_{2}$ composite were used as a catalyst to degrade the pesticide paraquat dichloride in the presence of UV light $(\lambda=257 \mathrm{~nm})$. The photodegradation process of paraquat dichloride takes place under 10 watts UV light irradiation and was measured using spectrophotometer UV. The maximum degradation percentage of pesticide paraquat dichloride photodegradation by chitosan- $\mathrm{Ti} / \mathrm{ZrO}{ }_{2}$ and chitosan- $\mathrm{ZrO}_{2}$ composites are $61.97 \%$ and $57.97 \%$ within 30 minutes irradiation time.
\end{abstract}

Keywords

Chitosan, Chitosan- $\mathrm{ZrO}_{2}$, Paraquat Dichloride, Photodegradation

Received: 6 April 2021, Accepted: 19 July 2021

https://doi.org/10.26554/sti.2021.6.3.204-208

\section{INTRODUCTION}

Paraquat dichloride (PQ) is a widely used pesticide in agriculture for the treatment of broadleaf and grassy weeds in various types of crops (Khodkar et al., 2019). Despite agricultural benefits, it is highly toxic to humans and animals and has the potential to cause membrane damage through lipid peroxidation by a free radical attack. Its toxicity to terrestrial and aquatic environments also raises serious concerns. Thus, it is very essential to treat wastewaters generated as a result of the production and application of $\mathrm{PQ}$ before disposal to secure the health of humans, wildlife and the aquatic environment (Eleburuike et al., 2016).

Several methods were used in treating wastewater such as coagulation, photodegradation, ozonation, biological treatment, filtration, etc (Kandisa et al., 2016; Safari et al., 2019; Siregar et al., 2021). The advantages of using photodegradation are, there is no sludge produced and foul odors are greatly reduced, safety application of the reactions being performed at atmospheric pressure and near ambient temperature and requires only dissolved oxygen in water (Wang et al., 2020b). Heterogeneous photocatalysis, which is one of the AOPs, is accepted as an efficient, cost-effective and environmentally friendly method of decontaminating water that has been polluted with pesticides and other organic compounds (Fil, 2016).

Shrimp shell from household waste is often not used and just becomes garbage, whereas shrimp shell waste can be used as an adsorbent and applied in waste treatment (Younes et al., 2012). Shrimp shell waste can be taken to produce chitin and synthesized into chitosan. Chitosan is a derivative of chitin, this compound is included in the biopolymer, it obtained from the alkaline deacetylation process of chitin (Teli and Sheikh, 2012). The yield of shrimp chitosan was also $15.4 \%$ more when compared to crab and squilla chitosan (Kumari et al., 2017).

Chitosan tends to be more reactive and easily dissolves in aqueous solutions. Chitosan can dissolve in organic and inorganic solvents because it has a free primary amino acid group spread evenly in its molecular chain, so chitosan is better used than chitin (Mohadi, 2015; Nwabor et al., 2020). To improve the ability to subscribe to organic compounds, chitosan was synthesized further by the addition of semiconductor compounds that have the photocatalytic ability, such as $\mathrm{TiO}_{2}, \mathrm{ZrO}_{2}$, etc. The titanium dioxide $\left(\mathrm{TiO}_{2}\right)$ nanotubes were synthesized using different $\mathrm{N}$-containing ligands and in this research, the oxide of $\mathrm{Ti} / \mathrm{ZrO}_{2}$ and $\mathrm{ZrO}_{2}$ immobilize into chitosan to form chitosan- $\mathrm{Ti} / \mathrm{ZrO}_{2}$ chitosan- $\mathrm{ZrO}_{2}$ composites (Mohadi et al., 2018).

According to previous research, composites materials mean 
the addition of properties into a combined material that can act as a photocatalyst which is then called a photocatalyst and on the other hand can be play a role as an adsorbent to overcome the weaknesses of conventional photocatalysts (Siregar et al., 2021). The composite means the addition of properties into a combined material that can act as a photocatalyst which is then called a photocatalyst and other hands can be as an adsorbent to overcome the weaknesses of conventional photocatalysts (Safari et al., 2019; Wang et al., 2020a). The chitosan- $\mathrm{Ti} / \mathrm{ZrO}_{2}$ chitosan- $\mathrm{ZrO}_{2}$ composites have been made with various approaches to produce materials that are more effective in reducing hazardous waste both in industrial waste and organic compounds waste, because chitosan is an adsorbent for the waste substance, while $\mathrm{Ti} / \mathrm{ZrO}_{2}$ and $\mathrm{ZrO}_{2}$ as photocatalytic agents. From the description, it is necessary to research the ability of chitosan- $\mathrm{Ti} / \mathrm{ZrO}_{2}$ chitosan- $\mathrm{ZrO}_{2}$ composites to reduce the concentration of paraquat dichloride pesticides in an aqueous medium by adsorption mechanism and besides that, it is also expected that chitosan- $\mathrm{Ti} / \mathrm{ZrO}_{2}$ chitosan- $\mathrm{ZrO}{ }_{2}$ composites from shrimp shell waste can be used to degrade paraquat dichloride pesticides by the photocatalytic process.

\section{MATERIALS AND METHODS}

The chemical reagents such as sodium hydroxide, hydrochloric acid, titanium dioxide, zirconyl chloride octahydrate were in analytical grade and used directly after being purchased from Merck without any further purification. The analytical instruments were Fourier Transform Infra-Red (FT-IR) spectroscopy Shimadzu Prestige-21, SEM-EDX JEOL JED-2300 and UV-Vis spectrophotometer Double Beam Shimadzu UV1800 .

\subsection{Preparation of Chitosan from Shrimp Shell}

The preparation of chitosan from shrimp shells was conducted by demineralization and deproteination processes (Teli and Sheikh, 2012). As much as $100 \mathrm{~g}$ of 60 mesh shrimp shell was put into a $500 \mathrm{~mL}$ beaker glass, then adding $1 \mathrm{M} \mathrm{HCl} \mathrm{solu-}$ tion with a ratio of $1: 10(\mathrm{w} / \mathrm{v})$. The mixture is stirred at room temperature for 3 hours at $60^{\circ} \mathrm{C}$, then filtered and the residue dried in an oven at $70^{\circ} \mathrm{C}$ until dry to constant weight. After the demineralization step the samples continue to the deproteination process, where the residue from demineralization step was put into a $500 \mathrm{~mL}$ beaker glass and added with $0.1 \mathrm{M} \mathrm{NaOH}$ solution at a ratio of 1:10 (w/v). The mixture was heated and stirred at $60^{\circ} \mathrm{C}$ for an hour and then filtered. Chitosan was dried in an oven at a temperature of $70^{\circ} \mathrm{C}$ until dry to constant weight. Chitosan has been obtained then characterized using FT-IR and SEM-EDX.

\subsection{Preparation of Chitosan- $\mathrm{Ti} / \mathrm{ZrO}_{2}$ and Chitosan- $\mathrm{ZrO}_{2}$ Composites}

An amount of $1.8 \mathrm{~g}$ of chitosan was added to $0.1 \mathrm{M} \mathrm{HCl} \mathrm{solu-}$ tion slowly and stirred with a magnetic stirrer until it dissolved completely. Then added $\mathrm{ZrO}_{2}$ with a ratio of 1:1 (w/w) with chitosan. The solution is then precipitate and filtered using filter

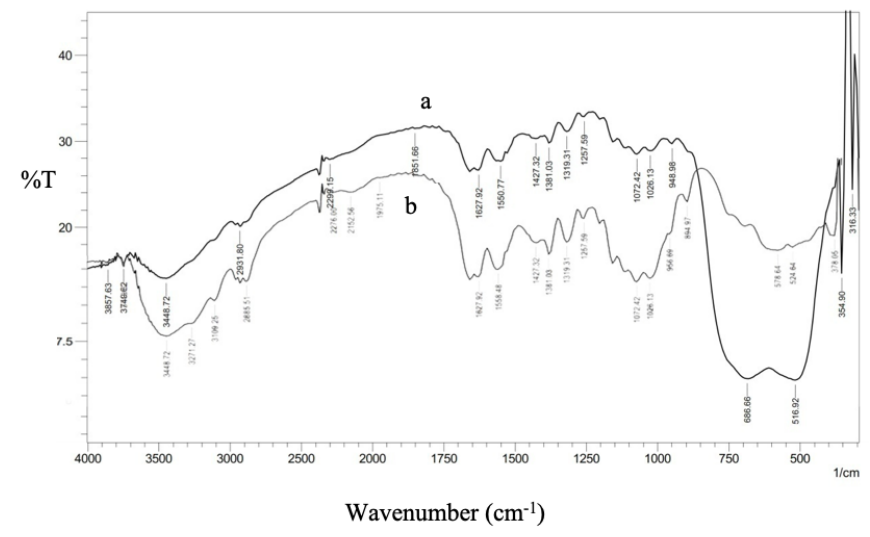

Figure 1. FT-IR Spectra for Chitosan- $\mathrm{Ti} / \mathrm{ZrO}_{2}$ (a) and Chitosan- $\mathrm{ZrO}_{2}$ (b) Composite

paper, from this process will be obtained chitosan- $\mathrm{ZrO}_{2}$ composite deposits. The residue is washed with distilled water until the $\mathrm{pH}$ is neutral. Then dried at $70^{\circ} \mathrm{C}$ using an oven, this step is repeated until the weight of chitosan- $\mathrm{ZrO}_{2}$ composite was constant. Chitosan- $\mathrm{ZrO}_{2}$ composite was then characterized by FT-IR to see its function group, and the surface morphology of Chitosan- $\mathrm{ZrO}_{2}$ composites was characterized by SEM-EDX. A similar procedure has been conducted to formed chitosan$\mathrm{Ti} / \mathrm{ZrO}_{2}$ which is the ratio of chitosan : $\mathrm{TiO}_{2}$ dan $\mathrm{ZrOCl}_{2}$ is $1: 1$. Then the obtained material has been characterized by FT-IR and SEM.

\subsection{Determination of Adsorption and Photodegradation Ca- pacity of Chitosan- $\mathrm{Ti} / \mathrm{ZrO}_{2}$ and Chitosan- $\mathrm{ZrO}_{2}$ Com- posite}

A total of four standard solutions of paraquat pesticides with a volume of $30 \mathrm{~mL}$ in various concentrations of $5,10,20$, and 40 $\mathrm{mg} / \mathrm{L}$ interact with $0.1 \mathrm{~g}$ chitosan- $\mathrm{Ti} / \mathrm{ZrO}_{2}$ and chitosan- $\mathrm{ZrO}_{2}$ composite for 30 minutes. The interaction was carried out in two different conditions, namely with or without irradiation of UV light. After 30 minutes the mixture was separated by centrifuge for 5 minutes at $5000 \mathrm{rpm}$. The filtrate was then measured using a UV spectrophotometer with $257 \mathrm{~nm}$ as the maximum absorbance wavelength.

\section{RESULTS AND DISCUSSION}

The chitosan modification that has been synthesized from shrimp shells was characterized by FT-IR Spectrophotometer and SEM-EDX to see the functional groups and the degree of deacetylation and the morphology of composite materials. FTIR spectrum data from chitosan- $\mathrm{Ti} / \mathrm{ZrO}_{2}$ and chitosan- $\mathrm{ZrO}_{2}$ composite were measured at a wavelength of $400 \mathrm{~cm}^{-1}-4000$ $\mathrm{cm}^{-1}$ as shown in Figure 1.

Figure 1 showed that the chitosan- $\mathrm{Ti} / \mathrm{ZrO}_{2}$ (a) and chitosan$\mathrm{ZrO}_{2}$ (b) composite has similar broad vibration between 3000$3750 \mathrm{~cm}^{-1}$ which indicates the presence of $-\mathrm{OH}$ and $-\mathrm{NH}_{2}$ groups which are active as chitosan. The presence of $-\mathrm{NH}_{2}$ 
stretching is mentioned in $3749.62 \mathrm{~cm}^{-1}$ and $-\mathrm{OH}$ stretching vibration at $3448.72 \mathrm{~cm}^{-1}$. Similar peaks of composite materials were also found at $2900-2930 \mathrm{~cm}^{-1}$ which indicated that the presence of -CH group (Younes et al., 2012). The bending vibration of the $-\mathrm{NH}$ amide group of the chitosan- $\mathrm{Ti} / \mathrm{ZrO}_{2}$ (a) and chitosan- $\mathrm{ZrO}_{2}$ (b) composite appeared at $1627.92 \mathrm{~cm}^{-1}$. The metal oxide vibrations of composites material appeared in $500-700 \mathrm{~cm}^{-1}$, which indicated O-Ti-O at $686.66 \mathrm{~cm}^{-1}$, and $\mathrm{O}-\mathrm{Zr}-\mathrm{O}$ from chitosan- $\mathrm{ZrO}_{2}$ composites will appear in an area of about $500 \mathrm{~cm}^{-1}$ temporarily from Figure 2 . The absorbance at a wavelength of $570.93 \mathrm{~cm}^{-1}$. Typical absorbance seen at wavenumbers below $1000 \mathrm{~cm}^{-1}$ indicates specific for inorganic compounds.

SEM analyses are important to investigate the structural properties of the composites. The morphologies of chitosan$\mathrm{Ti} / \mathrm{ZrO}_{2}$ and chitosan- $\mathrm{ZrO}_{2}$ composite were presented in Figure 2.

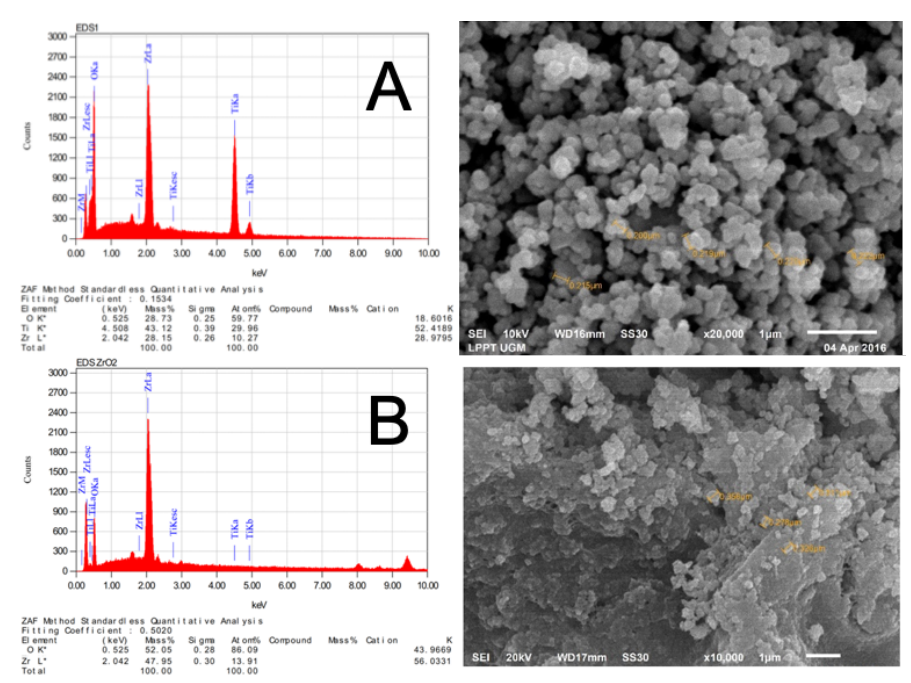

Figure 2. SEM-EDX Data for Chitosan-Ti/ $\mathrm{ZrO}_{2}$ (a) and Chitosan- $\mathrm{ZrO}_{2}$ (b) Composite

SEM images of chitosan- $\mathrm{Ti} / \mathrm{ZrO}_{2}$ (a) composite showed round-shaped particles on their surface, which indicates the $\mathrm{TiO}_{2}$ particles. The chitosan- $\mathrm{ZrO}_{2}$ (b) surface preserves the same round-shape structure which indicates the $\mathrm{ZrO}_{2}$ has been distributed but unevenly on the surface of chitosan. According to EDX results, $\mathrm{Ti}$ and $\mathrm{Zr}$ content in the composite materials was found in good agreement with $\mathrm{Zr}$ doping amount (Demircivi and Simsek, 2018).

\subsection{Photodegradation of Paraquat Chloride Pesticides Using Chitosan- $\mathrm{ZrO}_{2}$ Composite}

For effective photocatalytic degradation reactions of the composite materials can be achieved by the preliminary adsorption of the pollutant. Therefore, to investigate the adsorption equilibrium of the catalysts, dark adsorption experiments were conducted by g $10 \mathrm{mg}$ composite materials with $30 \mathrm{~mL}$ of varying concentration of to paraquat dichloride pesticide solution

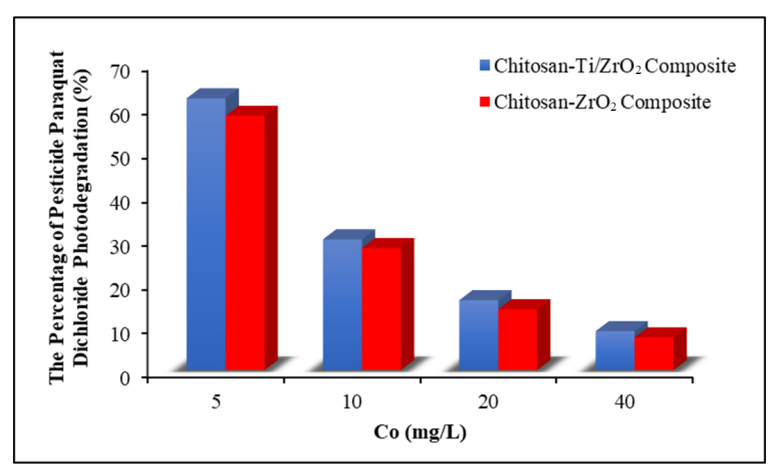

Figure 3. Percentage of Photodegradation of Pesticide Paraquat Dichloride by Chitosan- $\mathrm{Ti} / \mathrm{ZrO}_{2}$ (a) and Chitosan- $\mathrm{ZrO}_{2}$ (b) Composites at Various Concentrations

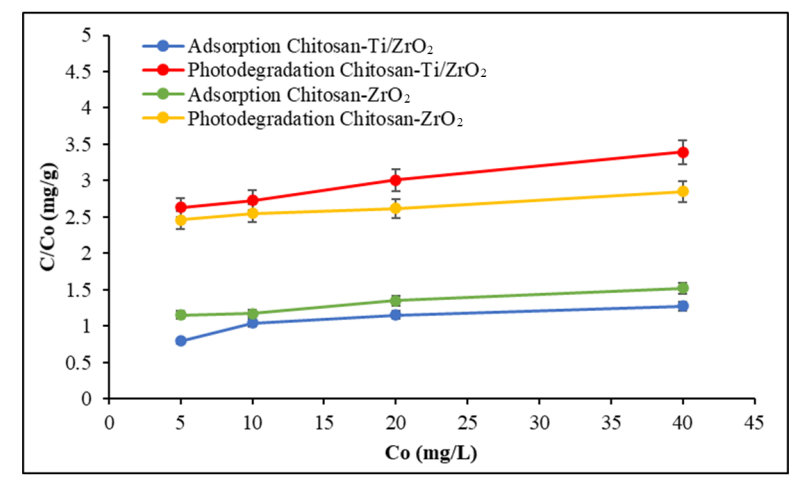

Figure 4. Graph of Comparison Between Removal Efficiency of Pesticide Paraquat Dichloride by Composite Materials using Adsorption and Photodegradation Treatment

under UV light radiation for 30 min shaking as shown as Figure 3.

The removal efficiency of chitosan- $\mathrm{Ti} / \mathrm{ZrO}_{2}$ (a) and chito san- $\mathrm{ZrO}_{2}$ (b) composite were found as 61.97 and $57.97 \%$ within $30 \mathrm{~min}$ at a lower concentration. The results of both composites materials showed that the photodegradation ability was decreased with concentration increasing of paraquat dichloride pesticides in an aqueous medium, this was possible due to weak interaction of the UV light with composite material when the concentration of absorbate is increased. These findings showed that the pesticide paraquat dichloride can be removed by composites materials. As the comparison, the study of comparison between adsorption and photodegradation using both composite materials onto pesticide paraquat dichloride has been presented in Figure 4.

Figure 4 showed that the removal efficiency of composite material has good ability using photodegradation treatment than adsorption treatment with the removal efficiency up to $3.39-2.85 \mathrm{mg} / \mathrm{g}$ for chitosan- $\mathrm{Ti} / \mathrm{ZrO}_{2}$ and chitosan$\mathrm{ZrO}_{2}$ composite, respectively. These findings showed that 
Table 1. Comparison the Results in Paraquat Dichloride Pesticides Degradation

\begin{tabular}{cccc}
\hline Degradation Agent & $\begin{array}{c}\text { Percentage } \\
\text { Degradation }\end{array}$ & $\begin{array}{c}\text { Degradation } \\
\text { time }\end{array}$ & References \\
\hline $\mathrm{W}_{-} \mathrm{TiO}_{2}$ (tungsten- & $98 \%$ & $6 \mathrm{~h}$ & (Kaur et al., 2019) \\
doped $\mathrm{P}_{25} \mathrm{TiO}_{2}$ ) & $60 \%$ & $3.5 \mathrm{~h}$ & (Moctezuma et al., 1999) \\
$\mathrm{TiO}_{2}$ & $59.96 \%$ & $2 \mathrm{~h}$ & (Teerakun et al., 2020) \\
Sphingomicrobium marinum & $51 \%$ & $3 \mathrm{~h}$ & (Eleburuike et al., 2016) \\
$\mathrm{CeO}_{2}$ - modified $\mathrm{TiO}_{2}$ nanotubes & $48 \%$ & $3.5 \mathrm{~h}$ & (Ali and Hassan, 2008) \\
$\mathrm{TiO}_{2}$ thin film & $35 \%$ & $4 \mathrm{~h}$ & (Razali et al., 2013) \\
$\mathrm{TiO}_{2}$ nanostructured & $51.22 \%$ & $4 \mathrm{~h}$ & (Ali and Hassan, 2008) \\
$\mathrm{TiO}_{2}-\mathrm{ZnO}$ & $57.64 \%$ & $2 \mathrm{~h}$ & (Arfi et al., 2017) \\
$\mathrm{ZnO}_{\text {Chitosan- } \mathrm{Ti} / \mathrm{ZrO}_{2} \text { composite }}^{61.97 \%}$ & 30 minutes & This work \\
Chitosan- $\mathrm{ZrO}_{2}$ composite & $57.97 \%$ & 30 minutes & This work \\
\hline
\end{tabular}

photodegradation treatment is twice bigger than the adsorption process with an adsorbed capacity of only $1.52-1.27 \mathrm{mg} / \mathrm{g}$. These phenomena assumed that the UV light degradation of pesticide paraquat dichloride to become small molecule than before to the small molecule can more easily adsorb (Arfi et al., 2017). Furthermore, in this study, the comparison of similar studies is shown in Table 1 . Table 1 showed that this study has a good percentage degradation with fast irradiation time.

\section{CONCLUSIONS}

The preparation of chitosan modified to formed chitosan$\mathrm{Ti} / \mathrm{ZrO}_{2}$ and chitosan- $\mathrm{ZrO}_{2}$ composites have been successfully prepared. FTIR spectra were showed similar peaks and characteristics of chitosan and metal oxide. The morphologies of SEM showed similar irregular round-shaped particles on the composite materials. The removal efficiency of chitosan$\mathrm{Ti} / \mathrm{ZrO}_{2}$ and chitosan- $\mathrm{ZrO}_{2}$ composite were found as 61.97 and $57.97 \%$ within $30 \mathrm{~min}$ at $5 \mathrm{mg} / \mathrm{L}$. Moreover, the pesticide paraquat dichloride photodegradation using chitosan$\mathrm{Ti} / \mathrm{ZrO}_{2}$ and chitosan- $\mathrm{ZrO}_{2}$ composite take less reaction time and higher degradation ability compared to the results of other studies.

\section{ACKNOWLEDGEMENT}

This research was supported from Hibah Kompetitif of Sriwijaya University 2020 through PNBP funding with approval letter number: 0179.048/UN9/SB3.LPPM.PT/2020. We also gratefully acknowledge to Research Center of Inorganic Materials and Complexes FMIPA Universitas Sriwijaya for instrumental analysis.

\section{REFERENCES}

Ali, R. and S. H. Hassan (2008). Degradation studies on paraquat and malathion using $\mathrm{TiO}_{2} / \mathrm{ZnO}$ based photocatalyst. The Malaysian Journal of Analytical Sciences, 12(1); 77-87

Arfi, F., S. Safni, and Z. Abdullah (2017). Degradation of
Paraquat in Gramoxone Pesticide with Addition of $\mathrm{ZnO}$. Molekul, 12(2); 159-165

Demircivi, P. and E. B. Simsek (2018). Fabrication of Zrdoped $\mathrm{TiO}_{2} /$ chitosan composite catalysts with enhanced visible-light-mediated photoactivity for the degradation of Orange II dye. Water Science and Technology, 78(3); 487-495

Eleburuike, N. A., W. A. W. A. Bakar, R. Ali, and M. F. Omar (2016). Photocatalytic degradation of paraquat dichloride over $\mathrm{CeO}_{2}$-modified $\mathrm{TiO}_{2}$ nanotubes and the optimization of parameters by response surface methodology. RSC advances, 6(106); 104082-104093

Fil, B. A. (2016). Isotherm, kinetic, and thermodynamic studies on the adsorption behavior of malachite green dye onto montmorillonite clay. Particulate Science and Technology, 34(1); 118-126

Kandisa, R. V., K. N. Saibaba, K. B. Shaik, R. Gopinath, et al. (2016). Dye removal by adsorption: a review. Journal of Bioremediation and Biodegradation, 7(6); 2-4

Kaur, M., A. Verma, H. Setia, and A. P. Toor (2019). Comparative Study on the Photocatalytic Degradation of Paraquat Using Tungsten-Doped $\mathrm{TiO}_{2}$ Under UV and Sunlight. Springer, Singapore

Khodkar, A., S. Khezri, A. Pendashteh, S. Khoramnejadian, and L. Mamani (2019). A designed experimental approach for photocatalytic degradation of paraquat using $\alpha$ - $\mathrm{Fe}_{2} \mathrm{O}_{3} @ \mathrm{MIL}-101(\mathrm{Cr}) @ \mathrm{TiO}_{2}$ based on metal-organic framework. International Journal of Environmental Science and Technology, 16(10); 5741-5756

Kumari, S., S. H. K. Annamareddy, S. Abanti, and P. K. Rath (2017). Physicochemical properties and characterization of chitosan synthesized from fish scales, crab and shrimp shells. International journal of biological macromolecules, 104; 1697-1705

Moctezuma, E., E. Leyva, E. Monreal, N. Villegas, and D. Infante (1999). Photocatalytic degradation of the herbicide "paraquat". Chemosphere, 39(3); 511-517

Mohadi, R. (2015). Synthesis Of Nanocomposite Chitosan- 
$\mathrm{TiO}_{2}$ And Its Application As Photodegradation Agent Of Methilen Blue In Aqueous Medium. Polish Scientific Journals Database, 20; 213-221

Mohadi, R., N. Hidayati, and A. Lesbani (2018). Isolation of $\beta$-Chitosan from Squid Bone as Raw Material to Synthesize of Hybrid Photocatalysts $\mathrm{TiO}_{2}$-Chitosan. Journal of Physics: Conference Series, 1095(1); 012032

Nwabor, O. F., S. Singh, S. Paosen, K. Vongkamjan, and S. P. Voravuthikunchai (2020). Enhancement of food shelf life with polyvinyl alcohol-chitosan nanocomposite films from bioactive Eucalyptus leaf extracts. Food Bioscience, 36; 100609

Razali, M. H., C. Ruslimie, W. M. Khairul, et al. (2013). Modification and performances of $\mathrm{TiO}_{2}$ photocatalyst towards degradation of paraquat dichloride. Journal of Sustainability Science and Management, 8(2); 244-253

Safari, S., K. von Gunten, M. S. Alam, M. Hubmann, T. A. Blewett, Z. Chi, and D. S. Alessi (2019). Biochar colloids and their use in contaminants removal. Biochar, 1(2); 151162

Siregar, P. M. S. B. N., N. R. Palapa, A. Wijaya, E. S. Fitri, and A. Lesbani (2021). Structural stability of Ni/Al layered double hydroxide supported on graphite and biochar toward adsorption of congo red. Science and Technology Indonesia, 6(2); 85-95

Teerakun, M., A. Reungsang, M. Chaowarat, and P. Saraphirom (2020). Optimization of paraquat degradation with microbial consortium from contaminated soil using statistic method. Int. J. Geomech, 18(68); 73-79

Teli, M. and J. Sheikh (2012). Extraction of chitosan from shrimp shells waste and application in antibacterial finishing of bamboo rayon. International journal of biological macromolecules, 50(5); 1195-1200

Wang, W., H. Wang, G. Li, P. K. Wong, and T. An (2020a). Visible light activation of persulfate by magnetic hydrochar for bacterial inactivation: Efficiency, recyclability and mechanisms. Water research, 176; 115746

Wang, Y., F. Jiang, J. Chen, X. Sun, T. Xian, and H. Yang (2020b). In situ construction of CNT/CuS hybrids and their application in photodegradation for removing organic dyes. Nanomaterials, 10(1); 178

Younes, I., O. Ghorbel-Bellaaj, R. Nasri, M. Chaabouni, M. Rinaudo, and M. Nasri (2012). Chitin and chitosan preparation from shrimp shells using optimized enzymatic deproteinization. Process Biochemistry, 47(12); 2032-2039 